tine oil and I part of concentrated sulphuric acid, mix them in a large china bowel and let the mixture stand for 24 hours; then decant the upper strata of the fluid, shake the portion with soda and subject to distillation at from $150^{\circ}$ to $160^{\circ} \mathrm{C}$. The purity of the product is to be tested by fuchsin which is absolutely impossible in a pure terebene, and by metlislene-violet and iodoform which are dissolved therein, the better the purer the preparation is. Moreover, a pure terebene disguises idoform odor most completely; in fact, is the best deodorisant for the drug yet known. The distillation gives the following products : I. A resin which is employed for disinfecting cess-pools, etc., and a fluid residuum. The fluid is subjected to a further distillation, and then gives 2. a gaseous terebene, and 3. a dark brown resin. The latter constitutes an excellent material for preparing terebene soaps and a terebene paper. The exceedingly cheap paper is prepared of 6 ounces of the resin with I ounce of oleum cocos, and $1 / 2$ ounce of paraffine. 4 When soaked in water, the resin gives a terebene lotion which represents a most valuable deodorizing and disinfectant means in surgical and obstetrical practice.-Transactions of the Third General Meeting of Russian Medical Men at St. Petersburg, 1889, No. Io.

\title{
HEAD AND NECK.
}

\section{Injection of Perchloride of Iron in Cavernous Angi-} oma of Cheek. By Prof. Nikolai Studensky (Kazan, Rus-sia). A hospital nurse, æt. 22 years, sought the writer's advice for a huge blue turgid tumor of her right cheek of 20 years' standing. The new growth reached from the upper edge of the auricle down to the chin, ( $16 \mathrm{~cm}$. ), and from the posterior edge of the ramus of the lower jaw up to the canine fossa and right augle of the mouth $(8 \mathrm{~cm}$.). It involved the whole thickness of the clieek $(6 \mathrm{~cm}$.) as well as the tonsil, and an adjacent portion of the soft palate. It disappeared on pressurc. On its cutaneous aspect there was seen a vertical scar representing a trace of some operative attempts which had been made by a country practitioner about three years before, to be given up in view of a tremendous hæmorrhage. The girl expressed an ardent desire to 
get rid of her tumor on account both of disfigurement and agonizing pain about the temporal region. At first, the introduction of silk ligatures through the new growth was tried by the author for 3 months. No diminution in size having ensued, Prof. Studensky commenced to inject into the tumor a 25 per cent solution of perchloride of iron, one drop every 5 or 6 days. Since the injection was invariably followed by an intense pain of about 3 days duration, and sometumes also by fever $\left(40^{\circ} \mathrm{C}\right.$.), he soon reduced the strength of the solution to ro per cent, the pain becoming somewhat more tolerable. A dense inflammatory infiltration set in around the puncture after each injection. Already, in a fortnight, a distinct shrinking could be noticed. In 5 or 6 months the tumor entirely lost its cavernous character, as far as the cutaneous aspect and the thickness of the cheek were concerned. It became dense, fibroid, and by far smaller later on, the author preceeded to inject the solution also into the affected tonsil and soft palate. $U p$ to the date (February, I888) as many as 200 injections have been made. Externally, there remain at present only slight traces of the former tumor, while the patient's general state is quite satisfactory, the temporal pain having disappeared. The treatment, however, is still continued, since, on any stoppage of $I$ or $\mathrm{I}^{1} / 2$ months duration, there come out here and there bluish, elastic, vascular nodules of a cavernous character. The injections are made into those ever appearing small angiomata. On the whole, however, Prof Studensky is obviously satisfied with the results achieved. $\mathrm{He}$ publishes his case to show that this old plan of dealing with an giomata, when practised with due caution, remains quite free from any grave complications (such as thrombosis and suppuration with lethal issue), which have been the cause of its fairly complete disappearance from the surgical horizon.-Khirurgitchesky Vestnik, March and April, I 888 .

II. Treatment of Pain after Teeth Extraction. By Dr. N. Beganovsky (St. Petersburg, Russia). The author divides cases of dental pain after teeth extraction into two distinct clinical categories, in one of which the symptom makes its appearance immediately after 